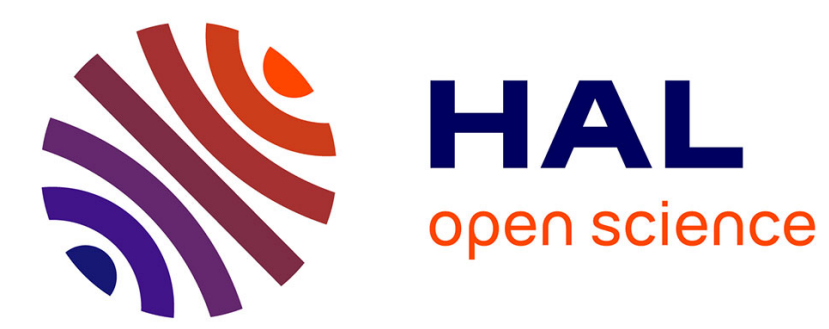

\title{
Counting the Holes
}

Roberto Casati, Achille Varzi

\section{To cite this version:}

Roberto Casati, Achille Varzi. Counting the Holes. Australasian Journal of Philosophy, 2004, 82, 1 (1), pp.23-27. 10.1080/713659800. ijn_01627170

\section{HAL Id: ijn_01627170 \\ https://hal.science/ijn_01627170}

Submitted on 1 Nov 2017

HAL is a multi-disciplinary open access archive for the deposit and dissemination of scientific research documents, whether they are published or not. The documents may come from teaching and research institutions in France or abroad, or from public or private research centers.
L'archive ouverte pluridisciplinaire HAL, est destinée au dépôt et à la diffusion de documents scientifiques de niveau recherche, publiés ou non, émanant des établissements d'enseignement et de recherche français ou étrangers, des laboratoires publics ou privés. 


\section{Counting the Holes}

Roberto Casati

Institut Jean Nicod, Centre National de la Recherche Scientifique, Paris

Achille C. Varzi

Department of Philosophy, Columbia University, New York

[Final version published in Australasian Journal of Philosophy 82:1 (2004), 23-27]

Abstract. Argle claimed that holes supervene on their material hosts, and that every truth about holes boils down to a truth about perforated things. This may well be right, assuming holes are perforations. But we still need an explicit theory of holes to do justice to the ordinary way of counting holes - or so says Cargle.

Cargle. I know where Argle and Bargle went wrong. ${ }^{1}$

Dargle. Concerning what?

Cargle. Concerning holes. Argle claimed that holes supervene on their material hosts, and that every truth about holes boils down to a truth about perforated things. This may well be right, assuming holes are perforations. (I suppose a similar theory can be worked out to account for our discourse about cuts, indentations, fissures, inner cavities, nooks, and the like.) But we still need an explicit theory of holes to do justice to the ordinary way of counting holes.

Dargle. Go ahead.

Cargle. For example, take this card—how many holes does it have?

Dargle. Obviously zero.

Cargle (punches a hole into the card). And now?

Dargle. Now there is one hole. But this is not to say that you have created an immaterial entity that should now be added to the inventory of the world. We

\footnotetext{
${ }^{1}$ Cf. [Lewis and Lewis 1970, 1996].
} 
can truly say that there is one hole in the card insofar as it is true that the card has been perforated, and everything we say about that hole can be paraphrased in terms of statements about this singly perforated card. If that is what Argle said, he was right. And don't tell me now that paraphrases can be hard to find, misleading, unnatural, or what have you-that is an empty can of worms. Nobody ever claimed that linguistic revision is easy.

Cargle. No quarrels about that. But why do you say that there is exactly one hole in the card?

Dargle. Because you have perforated it once.

Cargle. What if I punch it again? (Punches) There!

Dargle. Now you have a card with two holes-I mean, a doubly perforated card.

Cargle. Yes, that's what Argle would have said. And you are right, there are two holes now. By why do you identify the number of holes in the card with the number of times the card has been perforated?

Dargle. That is a simplification. Of course, some holes may not be the result of an intentional act of perforation. Other processes may be responsible for the break through.

Cargle. Then let me rephrase my question more generally. Why should we identify the number of holes in an object with the number of hole-creating processes?

Dargle. It's a simple topological fact. The number of hole-creating processes changes the topological genus of the object. Initially the genus of the card was equal to zero. Now it is equal to two: it has two more edges than the card you started with. Or: you can now make two edge-to-edge cuts without separating the card into two disconnected pieces. Or again: there are now two ways of hanging up the card on that nail on the wall. Many means are available to characterise the topological genus of the card without making any reference to the holes, so I don't see the problem. What would your answer be? How would you explain the fact that the card has these topological properties?

Cargle. I would turn things around. I would say that the card is doubly perforated because there are two holes in it. You say the card with its topology is the 
truth-maker of our statements concerning the holes in it. I say the truth-makers of your statements about the card's topology are the holes.

Dargle. But why two holes rather than one, if I may go back to your very own question?

Cargle. Well, you just see that. One hole here, one here. They are in different places and they came into being at different times.

Dargle. Why do you say "they"? Perhaps there is just one hole in the card-a hole split in two separate parts.

Cargle. I agree that appearance is no safe guide to reality. But here your scepticism is entirely ad hoc. In no other case you would say that there is a single, disconnected object where we intuitively count two, connected ones. Take these two pencils. You wouldn't say it is just one pencil with two separate parts, would you?

Dargle. I would not. But give me the red pencil. Now I break it in half-there! One pencil or two?

Cargle. Obviously just one pencil—a broken pencil.

Dargle. Now give me the yellow pencil. I sharpen it on both ends-there! One pencil or two?

Cargle. Again, just one. One pencil with two tips.

Dargle. And if I now break this in half—how many yellow pencils?

Cargle. Now I would say there are two yellow pencils.

Dargle. But if there is only one red pencil-a red pencil broken in half-why do you say there are two yellow pencils?

Cargle. Because... because I could use either one to write.

Dargle. ?

Cargle. (Ponders) OK, you are right. Let me just say that there appear to be two yellow pencils because each half appears to be a yellow pencil-a short, 
yellow pencil. Each appears to be a yellow pencil because of the tip. But there is only one pencil.

Dargle. But then the same could be true of the holes in the card. Speaking the language of the hole-realist, I could say there is only one hole in the card-a broken hole-even though there appear to be two. And there appear to be two holes insofar as each half looks like a hole.

Cargle. In the pencil case we know there is only one yellow pencil because we know where the parts come from. We know their history-you broke the pencil in half. Not so with the holes.

Dargle. I don't see the difference. We also know the history of these holes, or of this disconnected hole. I have not taken a hole and broken it in half, that's true. (I am not even sure one could break a hole in half-you tell me that.) But I have punched the card twice. And if you don't want to identify holes with the number of hole-creating processes, then you owe me an explanation of why I have made two holes rather than one, disconnected hole.

Cargle. This reminds me of the infamous U.S. Presidential elections of 2000. During the manual count in the Florida district, the canvassing board had troubles counting the number of holes in the ballots. So how did they proceed? They would hold up a ballot and check. A ballot with a see-through next to one candidate and another next to a different candidate would be discounted as void. The law says a voter can only express one preference. Two punchings—and the vote is null.

Dargle. You are falling back onto my criterion: the number of holes is the number of hole-creating processes...

Enter Zargle (showing up with a suitcase full of newspapers cut-outs). Wait a minute. In West Palm Beach the issue was precisely how to reckon the number of hole-creating processes. I have kept all the papers. On one theory, it was held that the recount should be driven by topological criteria: the genus of the ballot would determine the number of holes, hence the number of preferences expressed by the voter. (Only one preference admitted.) The competing theory held that the voters' attempts to express their preferences should be given priority. In some cases, it appeared that a voter made a mistake and then tried to correct it: the voter tried to express a preference for candidate A and then realised that she had punched the hole in the wrong place. So she tried to correct her vote by 
punching again next to candidate B. The first theory would disqualify such a ballot. The second theory would hold that in this case the voter did not punch a second hole but rather tried to correct the shape of the hole expressing her preference.

Dargle. Fine with me. The second theory corresponds to the view with which I was trying to challenge Cargle: a hole can have two disconnected parts.

Cargle. I would rather say that such voters didn't know they could only punch one hole.

Dargle. Let's be charitable. They knew that, and they intended to make a single hole.

Cargle. But then, if disconnected holes were admitted, there would be no way to determine a voter's intentions. How could the canvassing board establish whether someone first punched a hole next to A and then "enlarged" it by punching again next to $\mathrm{B}$, or vice versa?

Dargle. That only shows that the voting system is not fool-proof. It shows nothing concerning the metaphysics of holes. You still have to tell me what goes on in cases such as those: two holes-or one, disconnected hole?

Zargle. The committee might consider a new voting system, where each candidate is identified with a hole of a certain shape: a round hole for candidate A, a square hole for candidate $\mathrm{B}$, etc.

Cargle. And if you change your mind after punching a round hole?

Zargle. A star-shaped hole could be designed to indicate that the voter has corrected his or her vote from whatever to $\mathrm{B}$.

Dargle. Suppose I punch a star-shaped hole by mistake. I actually wanted to vote for A.

Zargle. Then you punch a diamond. A diamond-shaped hole trumps the starshaped one and indicates that you have corrected your vote from B to A.

Dargle. Sounds fishy to me. But I grant you that there are no problems in counting stars and diamonds. 
Cargle. Then why should there be any problems in counting holes? Holes come in different shapes, but their shape defines their identity. Just as there can't be disconnected star-shaped holes, there can't be disconnected XYZ-shaped holes. Period.

Dargle. Now this is ad hoc. Why would holes be so special as to enjoy this peculiar property? It can't be because they are immaterial, for that would be ad hoc, too. Material objects come in different sorts and you count objects by counting objects-of-a-sort. But you can't count objects tout court. I'm happy to count holes-of-a-sort, if you insist. But holes tout court can't be counted that way-unless they are just a façon de parler for the topological genus of their hosts, of course.

Cargle. Sometimes we do count material objects tout court. Distinct topologically connected, causally unitary chunks of matter count as distinct material objects. There is evidence that children begin to enumerate the entities in their environment by reference to such a criterion, even in the absence of any sortal concepts. All I am saying is that the same applies to immaterial entities such as holes (or cuts, indentations, fissures, etc., as well as silences, shadows, and much more) ${ }^{2}$

Dargle. If you are saying that some cognitive mechanisms have solved the problem of counting holes for children and adults - that they have solved it in your and my stead - then fine. But the problem remains of justifying that particular solution. Why does cognition favour the unitary?

Cargle. Because that's all there is.

Dargle. And what about non-unitary things, such as the broken red pencil? What is their place in the world, if cognition does not or even cannot acknowledge them? $?^{3}$

Cargle. I would say they don't exist, all things considered-mere ontological hallucinations.

Dargle. I would rather say they exist, all things considered-beware of ontological myopia!

${ }^{2}$ Cf. [Giralt and Bloom 2000] and [Bertamini and Croucher 2003].

${ }^{3}$ Cf. [Cartwright 1975]. 
Cargle. But you are the one who is being myopic about holes.

Dargle. You are the one who is hallucinating them.

Zargle. Here we go again. My dear sisters, you have reached the usual impasse. Nor could it be otherwise: such matters cannot be settled by argumentationyou should have learned from Argle and Bargle. So, now, rehearsed and refreshed, why don't we read again what they had to say?

\section{References}

Lewis, David and Stephanie Lewis 1970. Holes, Australasian Journal of Philosophy 48: 206-212 (reprinted in David Lewis's Philosophical Papers 1, New York: Oxford University Press, 1983: 3-9).

Lewis, David and Stephanie Lewis 1996. Casati and Varzi on Holes, Philosophical Review 105: 77-79 (reprinted in David Lewis's Papers in Metaphysics and Epistemology, Cambridge: Cambridge University Press, 1999: 183-186).

Giralt, Nuria and Paul Bloom 2000. How Special Are Objects? Children's Reasoning About Objects, Parts, and Holes, Psychological Science 11: 497-501.

Bertamini, Marco and Camilla J. Croucher 2003. The Shape of Holes, Cognition 87: $33-54$.

Cartwright, Richard 1975. Scattered Objects, in Analysis and Metaphysics, ed. K. Lehrer, Dordrecht: Reidel: 153-171. 